Int. J. Electrochem. Sci., 12 (2017) $10-21$

\title{
Electrochemical co-detection of Arsenic and Selenium on a Glassy Carbon Electrode Modified with Gold Nanoparticles
}

\author{
A.O. Idris ${ }^{1}$, N. Mabuba ${ }^{1}$, O.A. Arotiba $a^{1,2, *}$ \\ ${ }^{1}$ Department of Applied Chemistry, University of Johannesburg, PO Box 17011, Doornfontein 2028, \\ Johannesburg, South Africa, \\ ${ }^{2}$ Centre for Nanomaterials Science Research, University of Johannesburg, South Africa \\ *E-mail: oarotiba@uj.ac.za
}

doi: $10.20964 / 2017.01 .30$

Received: 23 September 2016 / Accepted: 29 October 2016 / Published: 12 December 2016

\begin{abstract}
In this paper, an electrochemical sensor based on anodic stripping voltammetric technique was prepared for the co-detection (simultaneous detection) of As(III) and Se(IV) in water. A glassy carbon electrode was modified with gold nanoparticle (AuNPs) via electrodeposition by cycling from $-400 \mathrm{mV}$ to 1100 $\mathrm{mV}$ and used as the substrate. The presence of AuNP on the electrode enhanced both the stripping current and peak resolution for both arsenic and selenium. The deposition potential, $\mathrm{pH}$ and choice of electrolytes were optimised. A detection limit of $0.15 \mathrm{ppb}$ (As(III)) and $0.22 \mathrm{ppb}$ (Se(IV)) was obtained with good reproducibility. The method was applied to real water sample and validated with inductively coupled plasma - optical emission spectroscopy.
\end{abstract}

Keywords: arsenic; selenium; gold nanoparticle; electrochemical co-detection; anodic stripping voltammetry

\section{FULL TEXT}

(C) 2017 The Authors. Published by ESG (www.electrochemsci.org). This article is an open access article distributed under the terms and conditions of the Creative Commons Attribution license (http://creativecommons.org/licenses/by/4.0/). 